\title{
Effect of Cations on the Oxidation and Atmospheric Corrosion of Iron Interfaces to Minerals
}

\author{
Chathura de Alwis ${ }^{1}$, Mikhail Trought ${ }^{1}$, Julia Lundeen ${ }^{2}$, Kathryn A. Perrine ${ }^{1, *}$ \\ ${ }^{1}$ Department of Chemistry, Michigan Technological University, Houghton, MI 49931 \\ ${ }^{2}$ Department of Materials Science \& Engineering, Michigan Technological University, \\ Houghton, MI 49931
}

Supporting Information

Figure S1: Raw PM-IRRAS spectra (uncorrected baseline)

Figure S2: Raw PM-IRRAS spectra of Fe in $\mathrm{CaCl}_{2}(\mathrm{aq})$ in $\mathrm{D}_{2} \mathrm{O}$

S4

Video description of real-time corrosion

S4-S5

Figure S3: Images of PM-IRRAS experiments

S5

Figure S4: ATR-FTIR spectra of $10 \mathrm{mM}$ solutions

S5-S6

Figure S5: XPS spectra of the O1s region of the mineral specimens

S7

Figure S6: XPS spectra of the C1s region of the mineral specimens

S8

Figure S7: XPS spectra of the Na1s and $\mathrm{Ca} 2 \mathrm{p}$ region of the corroded samples

S9

Figure S8: XPS spectra of the Fe2p region of the corroded samples

S10

Figure S9: XPS spectra of the $\mathrm{Fe} 2 \mathrm{p}$ and $\mathrm{Ca} 2 \mathrm{p}$ region of mineral specimens

S11

Table S1: XPS elemental composition of minerals

S12 
The raw PM-IRRAS spectra is shown below for iron (Iron II, 99.99\%, Allied Metals Corp.) and high purity iron (Puratronic, 99.995\%, Alfa Aesar) exposed to $10 \mathrm{mM} \mathrm{CaCl}_{2}$ (aq) or $10 \mathrm{mM}$ $\mathrm{NaCl}(\mathrm{aq})$. Figure S1A and S1C shows the PM-IRRAS spectra during adsorption of $\mathrm{O}_{2}$ and $\mathrm{CO}_{2}$ (from air) of iron after exposure to $10 \mathrm{mM} \mathrm{CaCl}_{2}$ (aq). The reflectance modes are clear in the few first spectra collected, but as $\mathrm{O}_{2}$ and $\mathrm{CO}_{2}$ (from air) is adsorbed to the interface region, the interfacial solution layer is disturbed due to the formation of $\mathrm{CaCO}_{3}$ species at the interface, thus distorting the Bessel function shape. Figure S1B and S1D shows PM-IRRAS spectra after the solution is completely removed from the analysis region on the sample and exposure to air (air oxidation). As $\mathrm{O}_{2}$ and $\mathrm{CO}_{2}$ is adsorbed to the iron interface, the $\delta \mathrm{OH}$ and the $v \mathrm{C}-\mathrm{O}$ indicate the growth of $\mathrm{CaCO}_{3}$ at the interface. Figure S1E and S1G shows the PM-IRRAS spectra during adsorption of $\mathrm{O}_{2}$ and $\mathrm{CO}_{2}$ (from air) of iron after exposure to $10 \mathrm{mM} \mathrm{NaCl}(\mathrm{aq}$ ), where $\delta \mathrm{OH}$ and the $\mathrm{vCO}_{3}$ modes show the growth of a carbonate film and the presence of solution phase water. After air oxidation in Figure $\mathrm{S} 1 \mathrm{~F}$ and $\mathrm{S} 1 \mathrm{H}$, the surface is oxidized forming a strong $v \mathrm{Fe}-\mathrm{CO}_{3}$ mode showing siderite is grown on the Fe interface. 

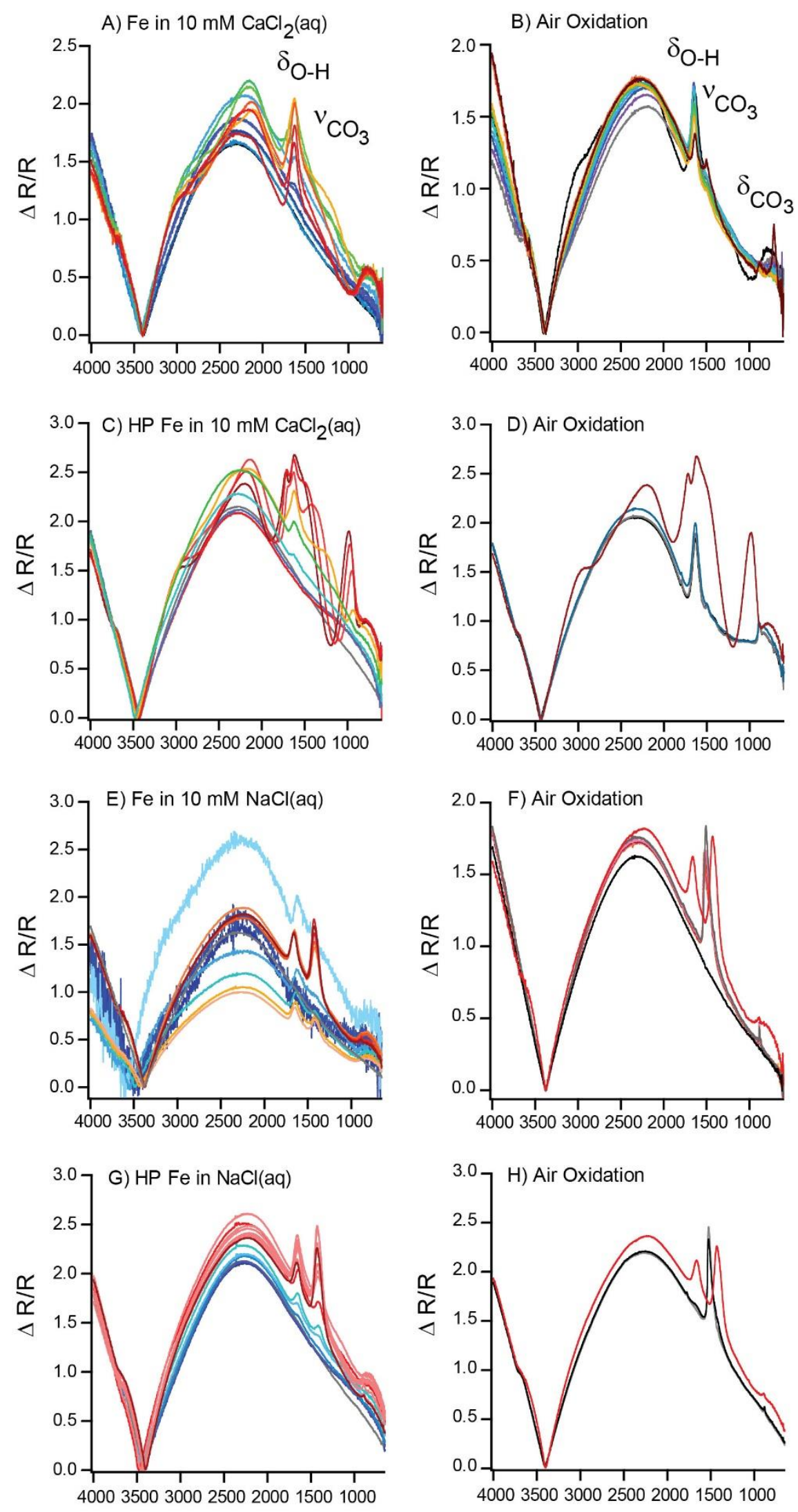

Wavenumber $\left(\mathrm{cm}^{-1}\right)$ 
Figure S1: Uncorrected PM-IRRAS spectra of A) Fe (99.99\%) surfaces exposed to $10 \mathrm{mM}$ $\mathrm{CaCl}_{2}$ (aq), B) A oxidized in air, C) high purity (HP, 99.995\%) Fe exposed to $10 \mathrm{mM} \mathrm{CaCl}$ (aq), D) $\mathrm{C}$ oxidized in air, E) HP (99.995\%) Fe exposed to $10 \mathrm{mM} \mathrm{NaCl}(\mathrm{aq})$, and $\mathrm{F}$ ) $\mathrm{E}$ oxidized in air. After the electrolyte solutions are removed allowing for oxidation in air $\left(\mathrm{O}_{2}\right.$ and $\left.\mathrm{CO}_{2}\right)$, sharp carbonate reflectance modes appear and remain constant with increasing time (minutes). This shows that in $\mathrm{B}$ ) and $\mathrm{D}$ ) $\mathrm{CaCO}_{3}$ is produced on the iron exposed to $\mathrm{CaCl}_{2}(\mathrm{aq})$ and $\mathrm{F}$ ) and $\mathrm{H}$ ) $\mathrm{FeCO}_{3}$ is grown on $\mathrm{Fe}$ exposed to $\mathrm{NaCl}(\mathrm{aq})$.

A) Fe in $10 \mathrm{mM} \mathrm{CaCl}_{2}(\mathrm{aq})$ in $\mathrm{D}_{2} \mathrm{O}$

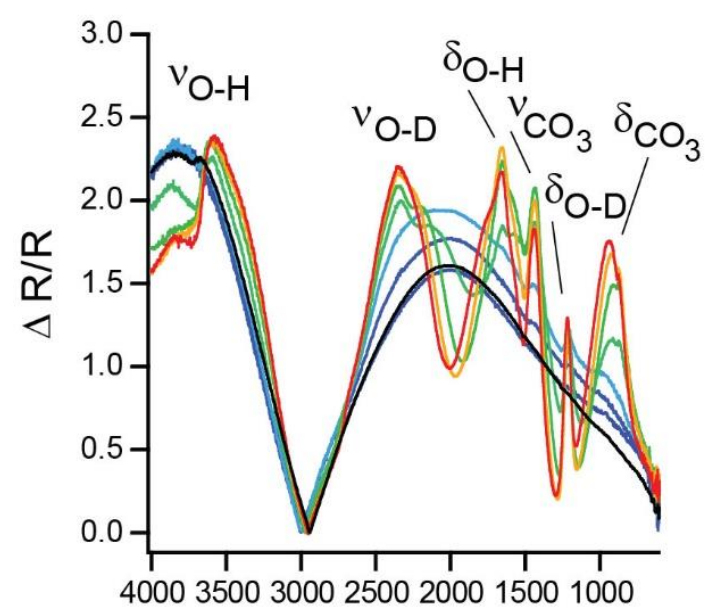

B) Air Oxidation

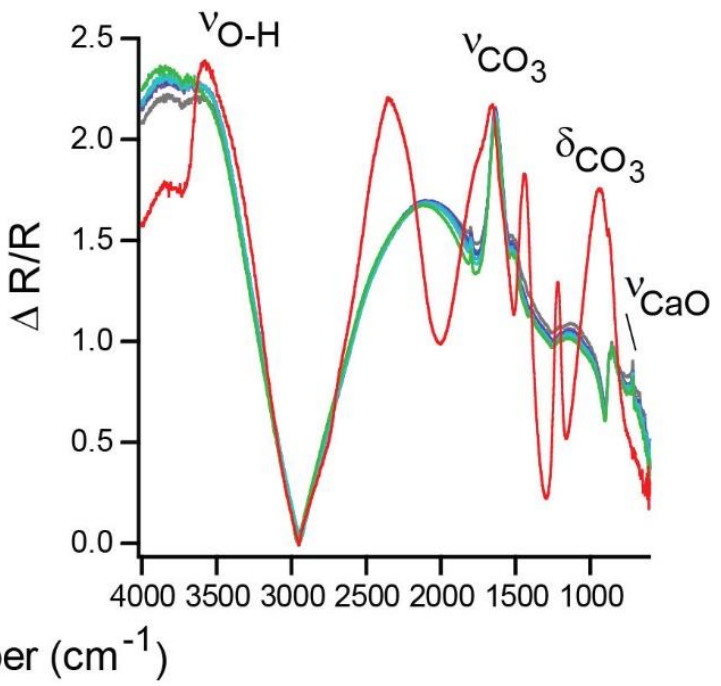

Figure S2: Fe exposed to $10 \mathrm{mM} \mathrm{CaCl}_{2}(\mathrm{aq})$ in $\mathrm{D}_{2} \mathrm{O}$. A) In stage 2, where the solution is removed to allow for atmospheric $\mathrm{O}_{2}$ and $\mathrm{CO}_{2}$ adsorption to the interface region, which distorts Bessel function. B) In stage 3, where the surface is completely oxidized in air, a surface carbonate is produced on the Fe surface. The $\mathrm{D}_{2} \mathrm{O}$ solvent is present when the liquid layer is present on the surface, as shown from the OD stretching and bending modes. Once the liquid layer is completely removed, the OD stretching and bending modes disappear.

Video timelapse description: Comparison of visible corrosion of high purity iron (99.995\%) with $10 \mathrm{mM} \mathrm{NaCl}(\mathrm{aq})$ (left sample) and $10 \mathrm{mM} \mathrm{CaCl}_{2}$ (aq) (right sample). A 95.2 minute video was compressed into 4 minutes, where 1 minute in the video is equal to 23.8 minutes (real time). The video shows pits are formed on the iron surfaces within the first 13 seconds ( 5 minutes real time). Rings are formed around the center of the pits that grow outward toward the edge of the droplets. At the time of 2 minutes ( 47 minutes real time), minerals are formed at the edges of the droplet shown by the dark brown and yellow colors (siderite in $\mathrm{NaCl}(\mathrm{aq})$ ) and calcite shown by the white ring (in $\mathrm{CaCl}_{2}$ (aq)). At 3 minutes and 10 seconds, the droplet is dried and the samples are oxidized in air to produce the signature lepidocrocite and hydroxy carbonate. Over time after the 3 minute mark, the (left) sample exposed to $\mathrm{NaCl}(\mathrm{aq})$ continues to oxidize in air in a gradual slow growth, while in air, the (right) sample exposed to $\mathrm{CaCl}_{2}$ (aq) oxidizes quickly and stops changing color. 
* Note the blinking in the camera and movement is a readjusting of the camera focus during the recording.

A) $\mathrm{HP} \mathrm{Fe}$ in $\mathrm{CaCl} 2(\mathrm{aq})$

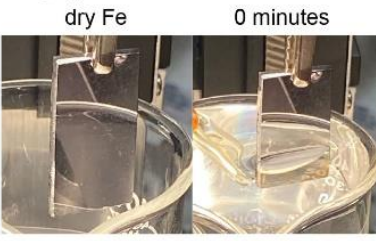

$23 m$

$117 \mathrm{~m}$

$128 \mathrm{~m}$

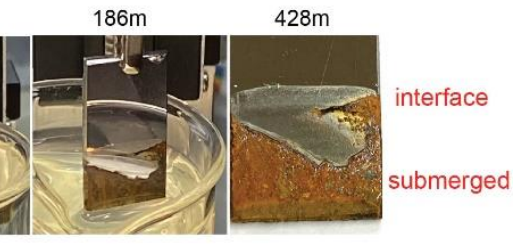

B) $\mathrm{HP} \mathrm{Fe}$ in $\mathrm{NaCl}(\mathrm{aq})$

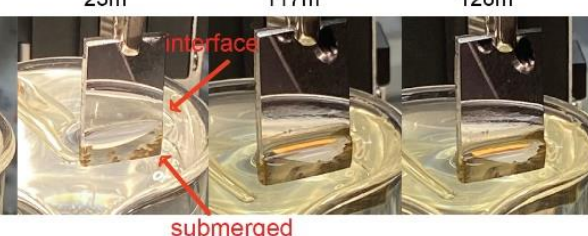

$82 \mathrm{~m}$

$144 \mathrm{~m}$

$196 \mathrm{~m}$

$244 \mathrm{~m}$

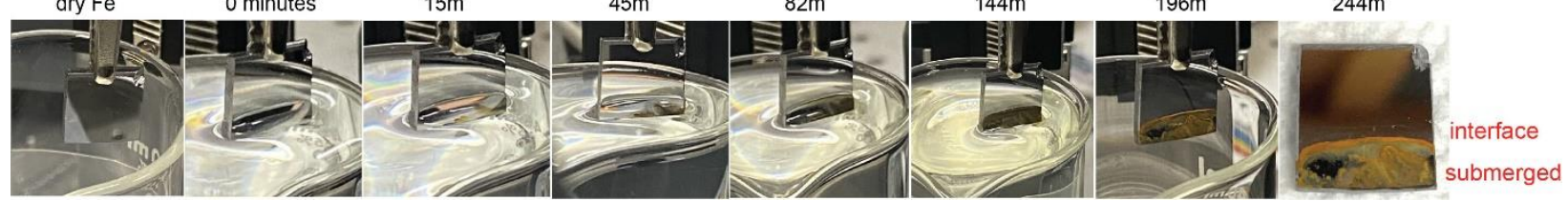

Figure S3: High purity (99.995\%) Fe in A) $10 \mathrm{mM} \mathrm{CaCl}_{2}$ (aq) over time (minutes) or B) $10 \mathrm{mM}$ $\mathrm{NaCl}(\mathrm{aq})$. Labels are given for the interface region, where atmospheric $\mathrm{O}_{2}(\mathrm{~g})$ and $\mathrm{CO}_{2}(\mathrm{~g})$ are gradually adsorbed to the interface, and the submerged region, where atmospheric $\mathrm{O}_{2}(\mathrm{~g})$ and $\mathrm{CO}_{2}(\mathrm{~g})$ are not exposed to the surface. Corrosion begins at the unpolished (rough) edges of the sample in solution. After the samples are completely oxidized in air, white films are observed for the grown $\mathrm{CaCO}_{3}$ and $\mathrm{FeCO}_{3}$ layers, while the submerged (corroded) region suggests lepidocrocite is produced.

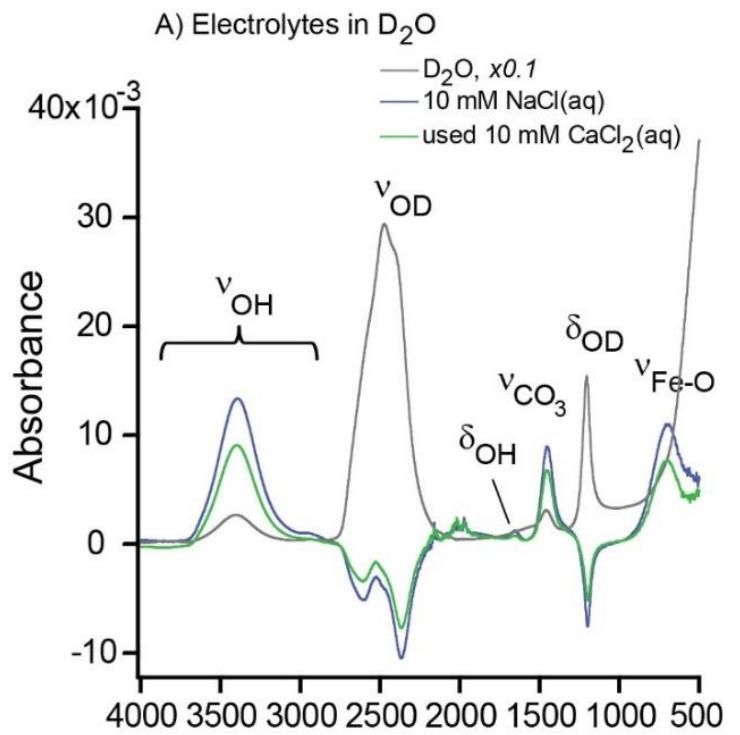

B) Electrolytes in $\mathrm{H}_{2} \mathrm{O}$

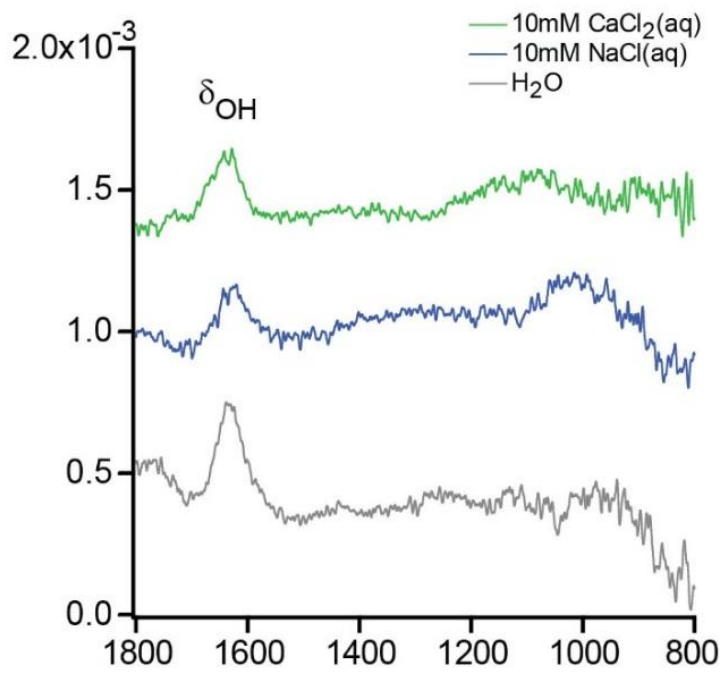

Wavenumber $\left(\mathrm{cm}^{-1}\right)$

Figure S4: ATR-FTIR spectra of the $\mathrm{NaCl}(\mathrm{aq})$ and the $\mathrm{CaCl}_{2}$ (aq) solutions in A) $\mathrm{D}_{2} \mathrm{O}$ and $\mathrm{B}$ ) $\mathrm{H}_{2} \mathrm{O}$ after the corrosion reaction using pure $\mathrm{D}_{2} \mathrm{O}$ or $\mathrm{H}_{2} \mathrm{O}$ as the background spectrum. The primary 
modes observe were the $\mathrm{OH}$ stretching and bending modes. Some presence of dissolved carbonates and iron oxides were also present. No visible evidence of carbonic acid was observed.

XPS spectra of surface corroded iron samples compared to natural mineral specimens is presented below. Mineral specimens for identification numbers are found in Table S1 below. All the XPS (survey/high resolution) regions were collected using a Mg anode X-ray source with an analysis region of $800 \mu \mathrm{m}$ diameter in spot size. Before collecting XPS spectra, the distance between the sample surface and the $\mathrm{Mg}$ anode was optimized to maximize the signal of the $\mathrm{C} 1 \mathrm{~s}$ peak at 284.6 $\mathrm{eV}$. Survey spectra of all the minerals were collected using a pass energy of $187.85 \mathrm{eV}$, a resolution of $0.8 \mathrm{eV} / \mathrm{step}$ and a dwell time of $20 \mathrm{~ms} / \mathrm{step}$. High resolution spectra of main constituent elements (C1s, O1s, Fe2p, Ca2p) and minor impurity elements (Cl2p, Si2p, N1s, S2p, P2p) were collected using a pass energy of $23.50 \mathrm{eV}$, a resolution of $0.1 \mathrm{eV} / \mathrm{step}$ and a dwell time of $100 \mathrm{~ms} / \mathrm{step}$. A Shirley background was used to deconvolute all the high resolution XPS regions using $100 \%$ Gaussian peak fits. All regions were charge corrected with respect to the adventitious C1s peak at 284.6 binding energy.

The deconvoluted XPS spectra of the O1s region of the natural minerals in Figure S5 help to identify surface species on the corroded samples when exposed to $\mathrm{CaCl}_{2}$ (aq) and $\mathrm{NaCl}(\mathrm{aq})$. The XPS fittings of the O1s region for the carbonate minerals have common surface species, such as iron oxide (Fe-O) within $530.7-529.2 \mathrm{eV}, \mathrm{CO}_{3}$ as the primary species at $531.5 \mathrm{eV}$, and adsorbed water centered at $533.5 \mathrm{eV} .{ }^{1}$ According to the XPS O1s region, aragonite does not contain any residual oxides as contaminants but only surface absorbed water from exposure to ambient conditions. The calcite mineral has a minute amount of oxide residues, whereas siderite has a considerable amount of iron oxides. The O1s region of lepidocrocite and goethite can also be deconvoluted to three species: Fe-O (529.4-529.7 eV), Fe-OH (530.6-531.4 eV), and adsorbed water (532.5-533.0 eV). 
A) 01 s region of carbonate minerals

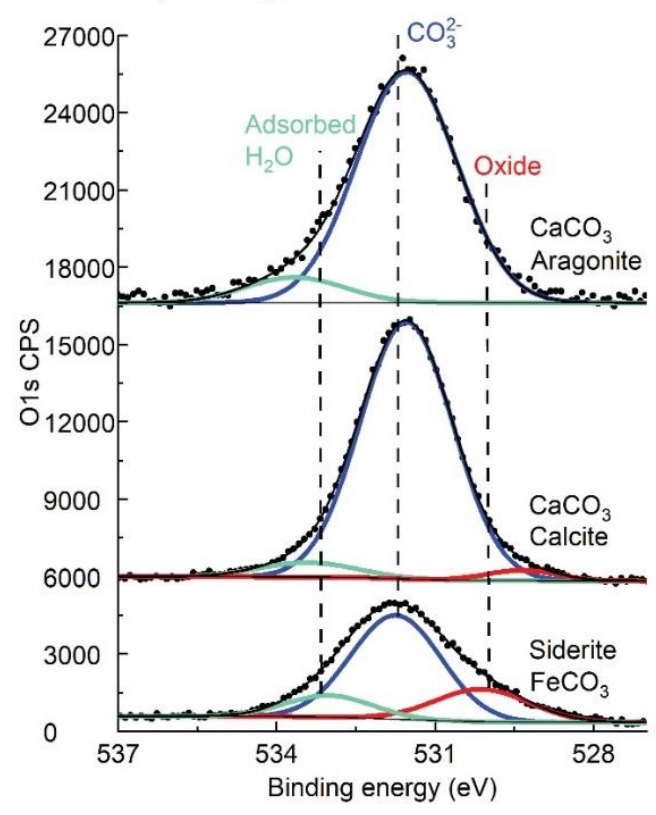

B) O1s region of iron oxyhydroxide minerals

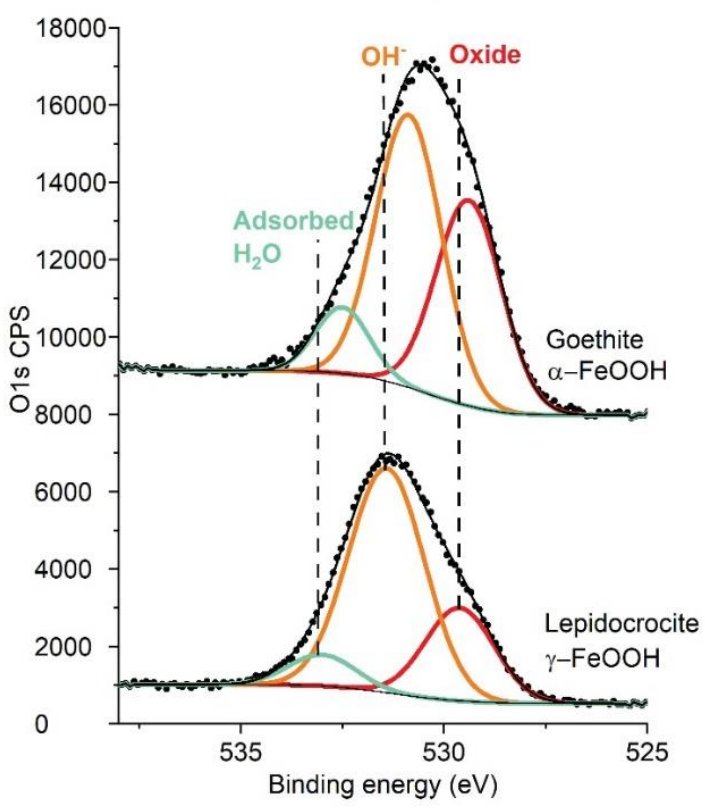

Figure S5: O1s region of natural mineral samples of A) carbonates (aragonite, calcite, siderite) and B) iron oxyhydroxides (goethite, lepidocrocite). 
The $\mathrm{C} 1 \mathrm{~s}$ region of five mineral samples (siderite, calcite, aragonite, lepidocrocite, and goethite) are given in the Figure S6 to compare with the XPS data collected for corroded Fe samples. The difference between iron carbonates and iron oxyhydroxides is the presence of a surface carbonate $\left(\mathrm{CO}_{3}\right)$ species (at 288.9-291.0 eV) that appears in the siderite, calcite, and aragonite minerals. This peak is absent in the lepidocrocite and goethite minerals. This characteristic feature is unique in identifying the formation of carbonates formed at Fe/electrolyte interfaces as a result of corrosion in $\mathrm{CaCl}_{2}(\mathrm{aq})$ and $\mathrm{NaCl}(\mathrm{aq})$.
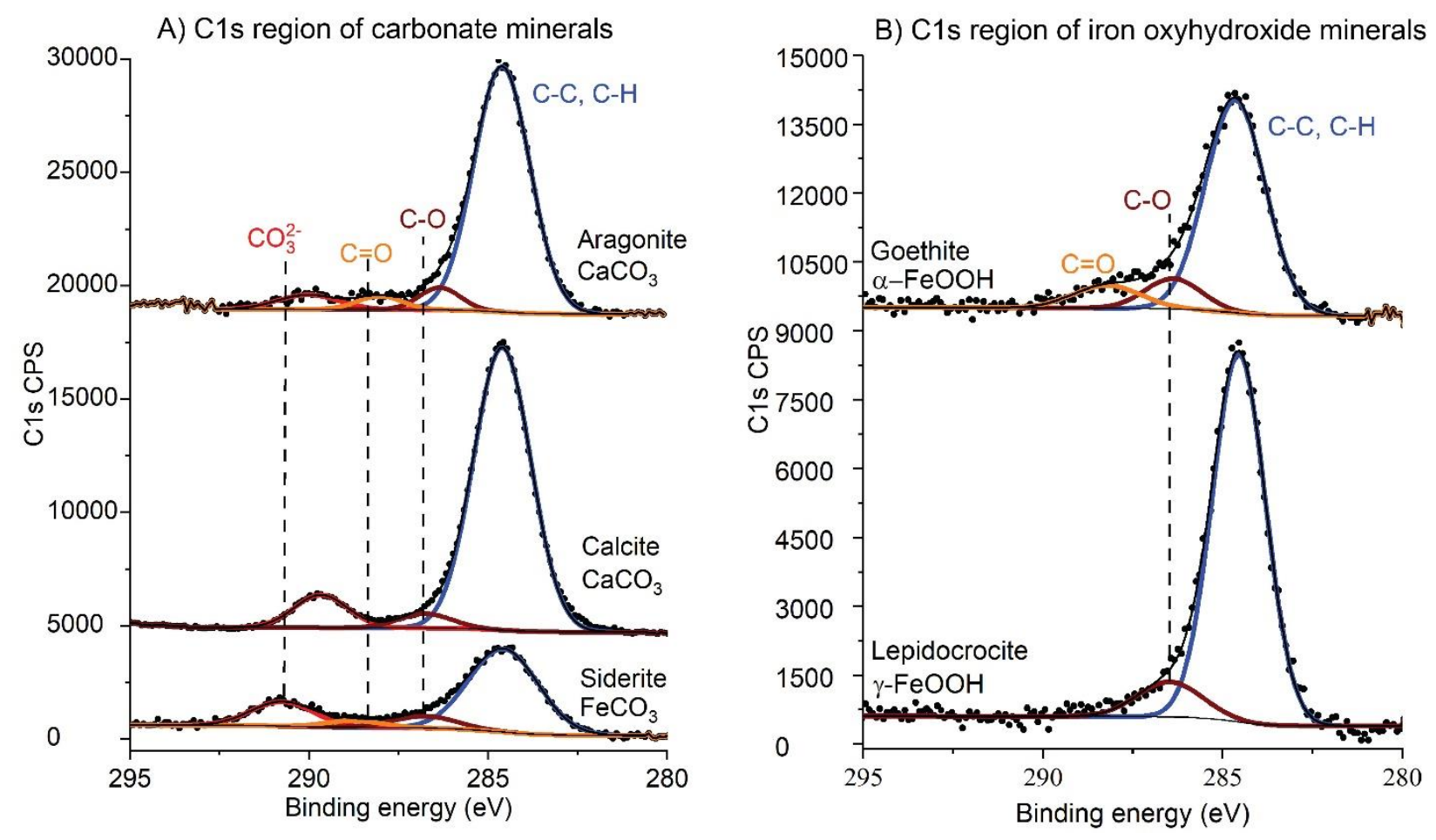

Figure S6: C1s region of natural mineral samples of carbonates (aragonite, calcite, siderite) and iron oxyhydroxides (goethite, lepidocrocite). 
Figure S7 shows the XPS spectra of the Na1s and Ca2p regions for three different regions of the iron samples (the interface region, the submerged region, and clean $\mathrm{Fe}$ ) produced from the PMIRRAS experiments. When iron is exposed to $10 \mathrm{mM} \mathrm{NaCl}(\mathrm{aq})$, some residual sodium remains on the surface ${ }^{2}$, as the sample is not rinsed before XPS analysis, as shown in Figure S7A. The binding energy of 1071.0-1071.4 eV is assigned to $\mathrm{NaCl}$, but also coincides with binding energies observed for $\mathrm{NaCO}_{3}$ on the iron surface. ${ }^{3} \mathrm{~A}$ small peak indicates the presence of Na-Fe at $1072.9-1073.8$ eV. In Figure S7B the XPS spectra of the Ca2p region also shows remaining $\mathrm{Ca}$ at the interface region and in the area of the sample that was submerged. The polished area of Fe used for PMIRRAS experiment with $10 \mathrm{mM} \mathrm{CaCl}_{2}$ (aq) electrolyte has a minute amount of $\mathrm{CaCl}_{2}$, from minor contamination. The interface and submerged regions $\left(\mathrm{CaCl}_{2} /\right.$ interface and in $\left.\mathrm{CaCl}_{2}(\mathrm{aq})\right)$ had direct contact with $\mathrm{CaCl}_{2}(\mathrm{aq})$ solution and show $\mathrm{Ca}$ species from leftover $\mathrm{CaCl}_{2}$ or formed $\mathrm{CaCO}_{3}$. ${ }^{4,5}$ Both $\mathrm{Ca}-\mathrm{Cl}$ and $\mathrm{CaCO}_{3}$ have similar $\mathrm{Ca} 2 \mathrm{p}^{3 / 2}$ binding energies between 347.6-347.9 eV (interface region) and $347.4 \mathrm{eV}$ (submerged region) ${ }^{5-7}$ Based on the ATR-FTIR spectra and PM-IRRAS analysis, the $\mathrm{Ca}$ binding energy is likely from the $\mathrm{CaCO}_{3}$ surface species. These binding energies are slightly higher compared to the aragonite and calcite Ca2p spectra in Figure S9 at 347.3-347.5 $\mathrm{eV}$.

A) Na1s region

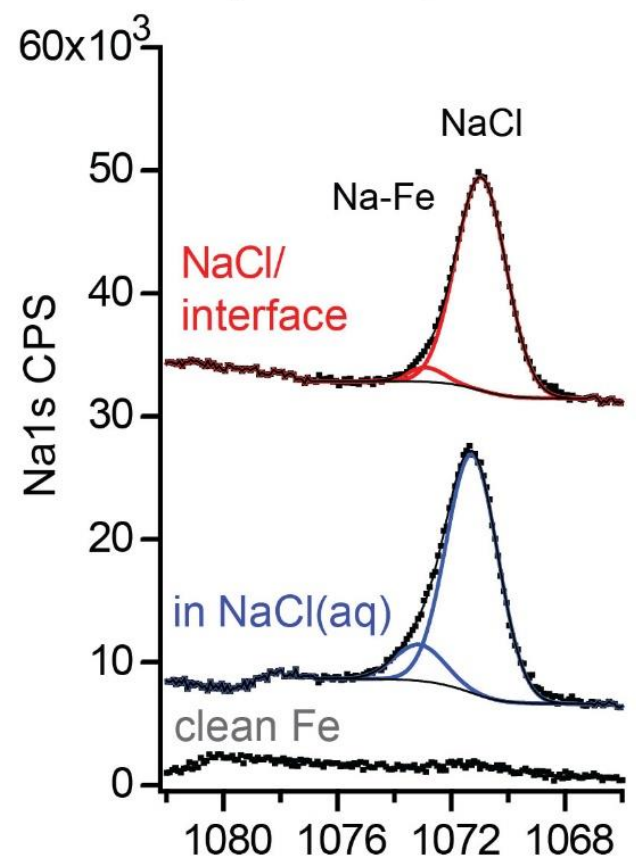

B) Ca2p region

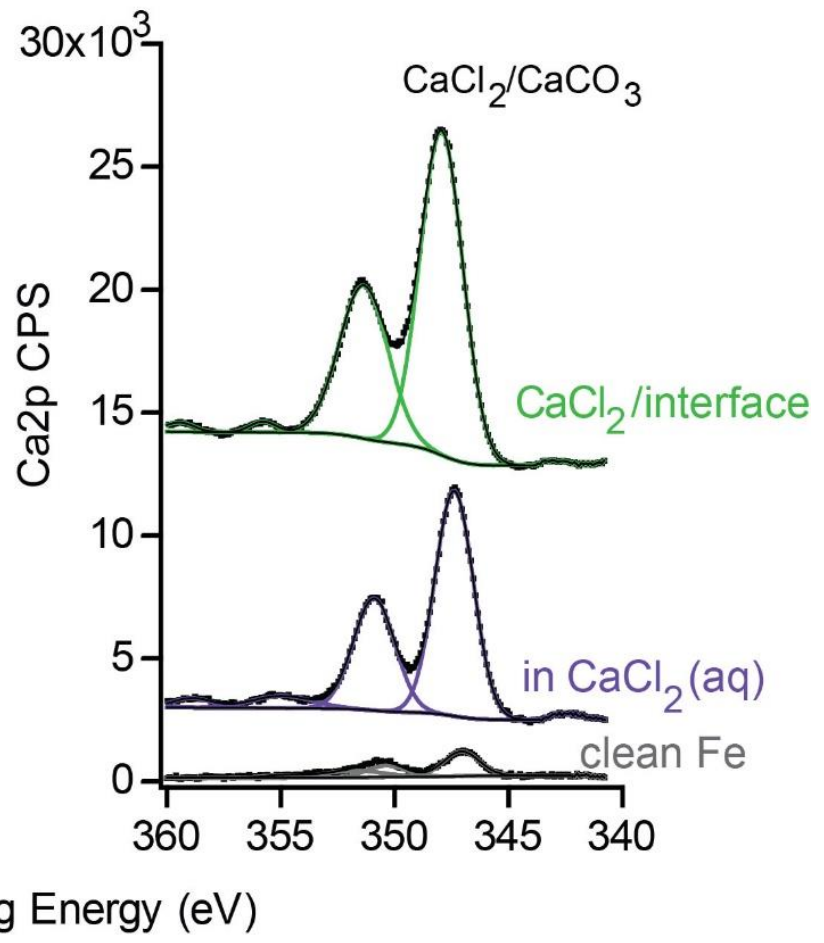

Figure S7: XPS spectra of the Na1s and Ca2p regions on the corroded iron surfaces for iron in the PM-IRRAS experiments. A) Iron exposed to $10 \mathrm{mM} \mathrm{NaCl}(\mathrm{aq})$ spectra at the interface region (red), iron submerged in the $\mathrm{NaCl}(\mathrm{aq})$ solution (blue), and clean iron (uncorroded, gray). B) Iron exposed to $10 \mathrm{mM} \mathrm{CaCl}$ (aq) spectra at the interface region (green), iron submerged in the $\mathrm{CaCl}_{2}(\mathrm{aq})$ solution (purple), and clean (polished) iron (uncorroded, gray). 


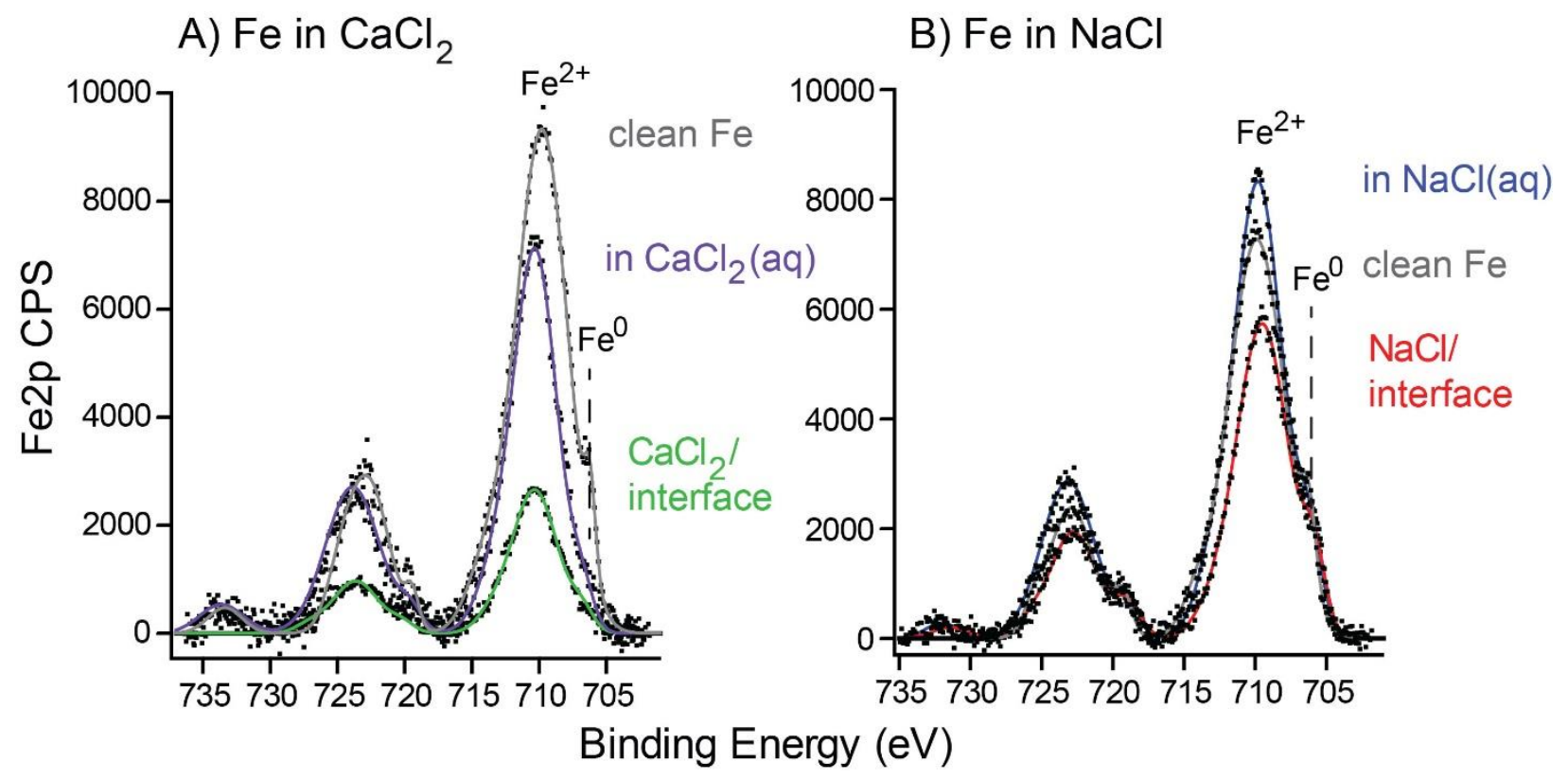

Figure S8: The comparison of the $\mathrm{Fe} 2 \mathrm{p}$ signal intensities for the iron surface exposed to $10 \mathrm{mM}$ A) $\mathrm{CaCl}_{2}$ (aq) and B) $\mathrm{NaCl}(\mathrm{aq})$. At the interface of iron exposed to $10 \mathrm{mM} \mathrm{CaCl}_{2}$ (aq), a $\mathrm{CaCO}_{3}$ layer is grown, reducing the signal of the $\mathrm{Fe} 2 \mathrm{p}$ region. The $\mathrm{Fe}^{0}$ is observed at a binding energy of $706.7 \mathrm{eV}$ and then is oxidized to $\mathrm{Fe}^{2+}$ or $\mathrm{Fe}^{3+}$ after corrosion, which are observed between 709.6$710.5 \mathrm{eV}$. When the iron surface is exposed to $10 \mathrm{mM} \mathrm{NaCl}(\mathrm{aq})$, the $\mathrm{Fe} 2 \mathrm{p}$ signals do not change significantly after the formation of $\mathrm{FeCO}_{3}$, suggesting the surface corroded, producing a thin film, while maintaining $\mathrm{Fe}^{0}$. 
Figure S9 shows the XPS Fe2p region of Fe containing minerals: siderite, lepidocrocite and goethite in comparison to the $\mathrm{Fe} 2 \mathrm{p}$ region of the corrosion products in Figure S4. No significant differences are observed between the spectra, though fundamentally the oxidation state of iron carbonate $\left(\mathrm{Fe}^{2+}\right)$ and oxyhydroxides $\left(\mathrm{Fe}^{3+}\right)$ are different. This is due to the difficultly in resolving the $\mathrm{Fe}^{2+}$ or $\mathrm{Fe}^{3+}$ binding energies. ${ }^{8-12}$ The $\mathrm{Ca} 2 \mathrm{p}$ region of aragonite and calcite shows binding energies of $347.5 \mathrm{eV}$ for aragonite and $347.3 \mathrm{eV}$ for calcite for the $\mathrm{Ca} 2 \mathrm{p}^{3 / 2}$ region..$^{5-7}$
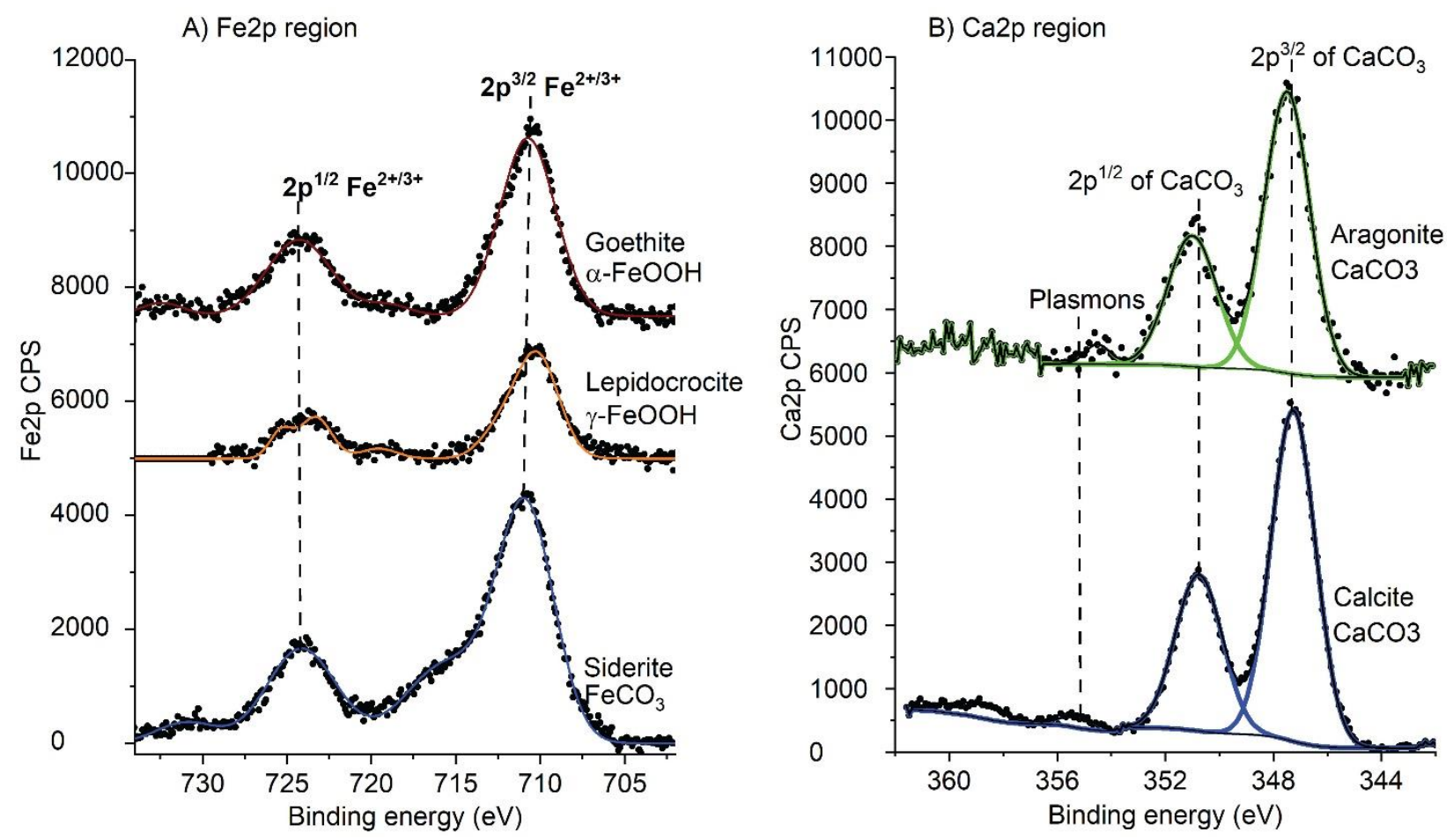

Figure S9: XPS spectra of the $\mathrm{Fe} 2 \mathrm{p}$ and $\mathrm{Ca} 2 \mathrm{p}$ regions for natural mineral samples. In the $\mathrm{Fe} 2 \mathrm{p}$ region, the minerals (from top to bottom) are presented: goethite $(\alpha-\mathrm{FeOOH})$, lepidocrocite $(\gamma$ $\mathrm{FeOOH})$, and siderite $\left(\mathrm{FeCO}_{3}\right)$. In the $\mathrm{Ca} 2 \mathrm{p}$ region, natural calcium mineral samples are presented (from top to bottom): aragonite and calcite (both $\mathrm{CaCO}_{3}$ ). 
Table S1 shows the relative percentages of the elements found on each mineral sample. One of the main trace elements is silicon species ( $\mathrm{SiOx})$, is common from its presence in the natural environment. Other trace elements that were identified were $\mathrm{Si}, \mathrm{Na}, \mathrm{Mg}, \mathrm{Ca}, \mathrm{S}, \mathrm{P}$, and $\mathrm{N}$. All the samples, with exception to goethite $(\alpha-\mathrm{FeOOH})$, contain carbon as the main surface chemical species from the surface contamination of ambient exposure. Fe was observed in all the mineral specimens that were measured, as $\mathrm{Fe}$ is a constituent element for $\mathrm{FeCO}_{3}, \alpha-\mathrm{FeOOH}$ and $\gamma-\mathrm{FeOOH}$. Iron was present as elemental contamination in $\mathrm{CaCO}_{3}$ (calcite and aragonite). ${ }^{13} \mathrm{Fe}$ and its derivatives are abundant in nature (soil, water) and this causes the contamination of minerals that do not have $\mathrm{Fe}$ in their structure. $\mathrm{Ca}$ was also observed as an impurity in the $\alpha-\mathrm{FeOOH}, \gamma-\mathrm{FeOOH}$, and $\mathrm{FeCO}_{3}$ mineral specimens. $\mathrm{Ca}$ is a constituent element for calcite and aragonite, although their relative percentage is smaller than what is suggested by the molecular formula, which is attributed to surface contamination.

Table S1: Mineral specimen elemental percentages. Concentrations of trace elements are present in the natural specimens. The samples were not sputtered prior to collecting XPS spectra.

\begin{tabular}{|c|c|c|c|c|c|c|c|c|c|c|c|c|c|}
\hline Mineral & Identification & C1s & O1s & Fe2p & $\mathrm{Ca} 2 \mathrm{p}$ & $\mathrm{Cl} 2 \mathrm{p}$ & Si2p & N1s & Na1s & $\operatorname{Mg2p}$ & S2p & $\mathbf{P} 2 p$ & F1s \\
\hline $\begin{array}{l}\text { Aragonite } \\
\left(\mathrm{CaCO}_{3}\right)\end{array}$ & DM-24902 & 62.3 & 24.3 & 1.8 & 4.7 & 0.0 & 0.3 & 0.8 & 0.0 & 1.1 & 2.6 & 2.2 & 0.0 \\
\hline $\begin{array}{c}\text { Calcite } \\
\left(\mathrm{CaCO}_{3}\right)\end{array}$ & N/A & 70.7 & 20.5 & 2.0 & 5.4 & 0.0 & 1.4 & 0.0 & 0.0 & 0.0 & 0.0 & 0.0 & 0.0 \\
\hline \multirow[t]{3}{*}{$\begin{array}{l}\text { Siderite } \\
\left(\mathrm{FeCO}_{3}\right)\end{array}$} & DM10517 & 56.0 & 31.5 & 8.7 & 0.0 & 0.0 & 0.0 & 1.6 & 2.2 & 0.0 & 0.0 & 0.0 & 0.0 \\
\hline & DM24308 & 56.6 & 23.3 & 3.2 & 1.4 & 0.3 & 3.0 & 0.0 & 0.0 & 1.3 & 0.0 & 10.9 & 0.0 \\
\hline & DM23948 & 69.2 & 21.1 & 3.4 & 0.0 & 0.2 & 0.0 & 1.7 & 0.5 & 4.0 & 0.0 & 0.0 & 0.0 \\
\hline $\begin{array}{c}\text { Goethite } \\
(\alpha-\mathrm{FeOOH})\end{array}$ & DM-4772 & 21.0 & 42.4 & 33.2 & 1.2 & 0.0 & 0.0 & 0.0 & 1.1 & 0.0 & 0.0 & 0.0 & 1.2 \\
\hline $\begin{array}{c}\text { Lepidocrocite } \\
(\gamma-\mathrm{FeOOH})\end{array}$ & DM-22910 & 61.5 & 24.8 & 5.4 & 2.2 & 0.0 & 2.4 & 0.0 & 0.0 & 2.8 & 0.0 & 1.0 & 0.0 \\
\hline
\end{tabular}




\section{References}

1. Liu, A. R.; Liu, J.; Pan, B. C.; Zhang, W. X., Formation of lepidocrocite (gamma$\mathrm{FeOOH}$ ) from oxidation of nanoscale zero-valent iron (nZVI) in oxygenated water. $R S C$ Advances 2014, 4 (101), 57377-57382.

2. Beard, B. C., Fresh Cleaved Single Crystal NaCl, XPS Spectra, Al Source Surface Science Spectra 1993, 2 (91), 91-96.

3. Shchukarev, A. V.; Korolkov, D. V., XPS study of group IA carbonates. Central European Journal of Chemistry 2004, 2 (2), 347-362.

4. Roychowdhury, T.; Bahr, S.; Dietrich, P.; Meyer, M.; Thissen, A.; Linford, M. R., Calcite $\left(\mathrm{CaCO}_{3}\right)$, by near-ambient pressure XPS. Surface Science Spectra 2019, 26, 014025.

5. Baer, D. R.; Moulder, J. F., High Resolution XPS Spectrum of Calcite $\left(\mathrm{CaCO}_{3}\right)$ Surface Science Spectra 1993, 2 (1).

6. Gopinath, C. S.; Hegde, S. G.; Ramaswamy, A. V.; Mahapatra, S., Photoernission studies of polymorphic CaCO3 materials. Materials Research Bulletin 2002, 37 (7), 1323-1332.

7. Demri, B.; Muster, D., XPS study of some calcium compounds. Journal of Materials Processing Technology 1995, 55 (3-4), 311-314.

8. Mansour, A. N.; Brizzolara, R. A., Characterization of the Surface of $\alpha$-FeOOH Powder by XPS Surface Science Spectra 1996, 4 (357).

9. $\quad$ Poulin, S.; Franca, R.; Moreau-Belanger, L.; Sacher, E., Confirmation of X-ray Photoelectron Spectroscopy Peak Attributions of Nanoparticulate Iron Oxides, Using Symmetric Peak Component Line Shapes. Journal of Physical Chemistry C 2010, 114 (24), 10711-10718.

10. Biesinger, M. C.; Payne, B. P.; Grosvenor, A. P.; Lau, L. W. M.; Gerson, A. R.; Smart, R. S., Resolving surface chemical states in XPS analysis of first row transition metals, oxides and hydroxides: Cr, Mn, Fe, Co and Ni. Applied Surface Science 2011, 257 (7), 2717-2730. 11. Bagus, P. S.; Nelin, C. J.; Brundle, C. R.; Crist, B. V.; Lahiri, N.; Rosso, K. M., Covalency in $\mathrm{Fe}_{2} \mathrm{O}_{3}$ and $\mathrm{FeO}$ : Consequences for XPS satellite intensity. Journal of Chemical Physics 2020, 153 (19).

12. Bagus, P. S.; Nelin, C. J.; Brundle, C. R.; Lahiri, N.; Ilton, E. S.; Rosso, K. M., Analysis of the Fe 2p XPS for hematite alpha $\mathrm{Fe}_{2} \mathrm{O}_{3}$ : Consequences of covalent bonding and orbital splittings on multiplet splittings. Journal of Chemical Physics 2020, 152 (1).

13. Yuan, K.; Lee, S. S.; Wang, J.; Sturchio, N. C.; Fenter, P., Templating Growth of a Pseudomorphic Lepidocrocite Microshell at the Calcite-Water Interface. Chemistry of Materials 2018, 30 (3), 700-707. 